\title{
Repetitive Strain Injury (RSI) Amongst Staff and Students of Computer Science Department of Kwame Nkrumah University of Science and Technology (KNUST)
}

\author{
Benjamin Odoi-Lartey \\ KNUST \\ Computer Science Department \\ Kumasi Ghana
}

\author{
Stephanie Mensah Opoku \\ KNUST \\ Computer Science Department \\ Kumasi Ghana
}

\author{
Edward Danso Ansong \\ KNUST \\ Computer Science Department \\ Kumasi Ghana
}

\begin{abstract}
Computers have now become a part of the day to day activities of almost every field of human work including education, health, agriculture, etc. Many people now work for longer hours due to the aid of computers. With the much benefits these computers, also comes the numerous problems which they pose on users, with Repetitive Strain Injury (RSI) being the commonest among them. Different approach such as questionnaires and personal interviews were used in the quest for these symptoms among various users of computers within the Computer Science Department of KNUST. The result obtained showed that majority suffered from pain in one or more parts of the body, that is, eyestrain, low back pain, wrist pain, finger pain or foot pain. These were all due to the duration of computer usage, size and type of monitors used, the type of chair used, the level of brightness of screens among others it was then discovered that the number of hours spent on computers are relative to the causes of pain in one or more parts of the body, hence increases the chances of being exposed to RSI.
\end{abstract}

\section{Keywords}

Repetitive Strain Injury (RSI), Scoliosis, Eyestrain, Ergonomics, Neck-injury, Waist, BMI, Obesity

\section{INTRODUCTION}

The globalization of the world has made it so essential for computer usage in recent times. This is due to the fact that computer offer a lot of different services and facilities to help the users to perform and complete tasks more efficient and effective from everywhere. Common injuries associated with its usage have also been recognized and being dealt with accordingly worldwide. Chair types being used at workplaces and homes, as well as poor prolonged sitting postures have been big factors to RSI causes. [2][12]

Repetitive Strain Injuries (RSIs) have recently being reported among several workers in the workplace, resulting in severe pains leading to impairment. Studies have showed that this is due to the overuse of computer system. This problem is preventable in most cases, hence the need to educate the users of computers about the problems and the extent of damage RSI can bring [1] [3][7]

\section{PROBLEM STATEMENT}

Introduction of computers has contributed to the multitude of health concerns, such as stiffness (neck, arm shoulders), back pain, headaches, eyestrain etc. which are commonly referred to as Repetitive Strain Injury, also called musculoskeletal strain (Compensation Commission, 2004; Silman \& Newman, 1996). This can lead a more serious and chronic symptom, which can eventually reduce the working span of an individual if not addressed [8] [9]

\section{LITERATURE REVIEW}

Adedoyin et al (2016) did a survey of computer users across six university campuses. His result showed that low back pain, finger pain, neck pain and shoulder pain are rated to be moderate, while all other joints pains were said to be mild. His study indicated that low back pain, neck pain and upper limbs are the common disorders complaints among the users. He attributed the cause of the pains to bad ergonomics among the users. [2] [4]

The South African Employee Health and Wellness Survey (SAEHWS) conducted a survey to determine if workers experience any RSI symptoms through questionnaires. [10]

Many of the studies conducted were focused on occurrence within the workplace and mostly University community.

\section{RESEARCH METHODOLOGY}

\subsection{Research Methodology Adopted}

This paper adopted a mixture of Qualitative and Quantitative approach through administering questionnaire and Interviews to gather data and coded this data in simple formats which is further interpreted with tabular and graphical formats.

Questionnaires and personal interviews were the instruments used for data collection. The questionnaires were design to suit each sector one finds him/herself. The questionnaire was divided into personal bio-data (staff or student), general ergonomic factors, BMI (Body-Mass Index) and level of exercise and breaks.

On a personal level, interactions were made with students and staff among the university community in the Computer Science Department precisely with regards to their experiences and the knowledge level with such symptoms.

\subsection{Statistical Analysis}

The data obtained were analyzed using the Statistical Package for the Social Sciences (SPSS) software with graphs and pie charts generated for a better understanding of the whole process. Descriptive statistics was used to analyze the data, with the experience of RSI determined through frequencies. 


\section{RESULTS}

\subsection{Data from Interviewees}

Table 1 indicates the age and the gender range of the interviewees involved in the conducted survey concerning age range of users of computer systems from age 1-17, 18-35, 3650 and 51-60. The age cap is set to end at 60years since that is the retirement age specified in Ghana's constitution.

Tab 1. Gender and Age Demographic of Interviewees

\begin{tabular}{|c|c|c|}
\hline & Frequency & Percentage \\
\hline Age(yrs.) & & 4.1 \\
\hline $1-17$ & 36 & 61.9 \\
\hline $18-35$ & 545 & 25.8 \\
\hline $36-50$ & 227 & 8.2 \\
\hline $51-60$ & 73 & \\
\hline Total & $\mathbf{8 8 1}$ & Percentage (\%) \\
\hline Gender & Frequency & 56.4 \\
\hline Male & 497 & 43.6 \\
\hline Female & 384 & \\
\hline
\end{tabular}

\section{Demographics of Interviewees}

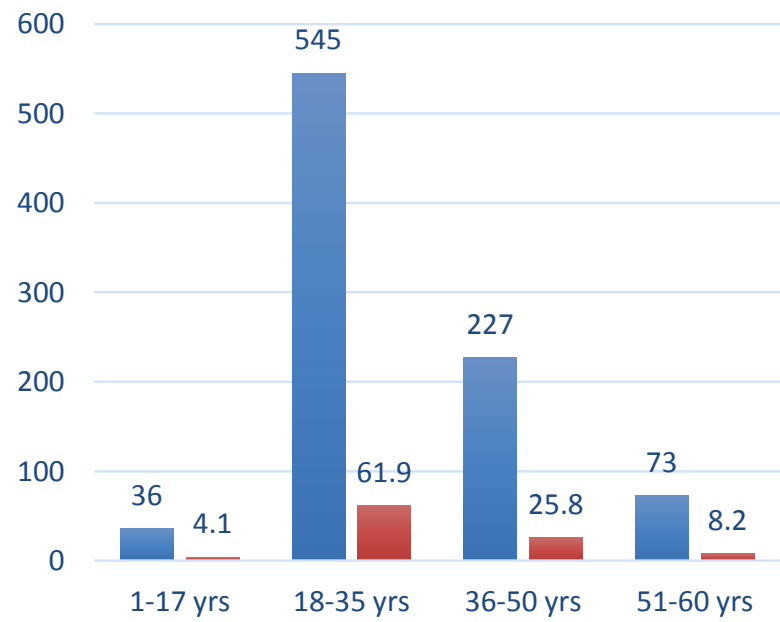

Fig 1. Bar graph of ages of Interviewees

Tab 2. Daily hours on Computer demographics

\begin{tabular}{|c|c|c|}
\hline \multicolumn{3}{|c|}{ Hours of Computer Usage } \\
\hline & Frequency & Percentage (\%) \\
\hline < 1 hour & 23 & 2.6 \\
\hline 1-3 hours & 72 & 8.2 \\
\hline 4-5 hours & 269 & 30.5 \\
\hline 6-7 hours & 392 & 44.5 \\
\hline$>$ 7 hours & 125 & 14.2 \\
\hline
\end{tabular}

Tab 3. Computer Usage demographics

\begin{tabular}{|c|c|c|}
\hline \multicolumn{3}{|c|}{ Computer Usage Information } \\
\hline \multicolumn{3}{|c|}{ Number of Years } \\
\hline & Frequency & Percentage (\%) \\
\hline <1 year & 26 & 3.0 \\
\hline 1-4 years & 272 & 30.9 \\
\hline 5-8 years & 396 & 44.9 \\
\hline$>$ 8 years & 187 & 21.2 \\
\hline
\end{tabular}

Tab 4. Chair-Type Used Demographics

\begin{tabular}{|c|c|c|}
\hline Chair-Type & Frequency & Percentage (\%) \\
\hline Adjust & 107 & 12.1 \\
\hline Fixed & 774 & 87.9 \\
\hline
\end{tabular}

Interviewees were asked to indicate the pains experienced. The table below indicates the various sufferings on their respective levels;

Tab 5. Chair-Type Used Demographics

\begin{tabular}{|c|c|c|c|c|c|c|}
\hline \multicolumn{7}{|c|}{ Total Number of Interviewees: 881 } \\
\hline Pain & $\mathbf{0}$ & $\mathbf{1}$ & $\mathbf{2}$ & $\mathbf{3}$ & $\mathbf{4}$ & Total \\
\hline Neck & $3 \%$ & $9 \%$ & $13 \%$ & $25 \%$ & $17 \%$ & $67 \%$ \\
\hline Arm & $6 \%$ & $11 \%$ & $23 \%$ & $12 \%$ & $7 \%$ & $59 \%$ \\
\hline Knee & $11 \%$ & $8 \%$ & $13 \%$ & $4 \%$ & $2 \%$ & $38 \%$ \\
\hline Head & $3 \%$ & $8 \%$ & $18 \%$ & $9 \%$ & $7 \%$ & $45 \%$ \\
\hline Body & $1.5 \%$ & $10 \%$ & $22.5 \%$ & $11 \%$ & $9 \%$ & $54 \%$ \\
\hline Eye & $2 \%$ & $4 \%$ & $15 \%$ & $21 \%$ & $41 \%$ & $83 \%$ \\
\hline Shoulder & $7 \%$ & $8 \%$ & $6 \%$ & $13 \%$ & $10 \%$ & $44 \%$ \\
\hline Elbow & $17 \%$ & $1 \%$ & $2 \%$ & $1 \%$ & $3 \%$ & $24 \%$ \\
\hline Wrist & $4 \%$ & $21 \%$ & $19 \%$ & $12 \%$ & $16 \%$ & $67 \%$ \\
\hline Finger & $6 \%$ & $14 \%$ & $22 \%$ & $14 \%$ & $8 \%$ & $64 \%$ \\
\hline Back & $13 \%$ & $17 \%$ & $19 \%$ & $11 \%$ & $9 \%$ & $69 \%$ \\
\hline Waist & $4 \%$ & $6 \%$ & $7 \%$ & $13 \%$ & $2 \%$ & $32 \%$ \\
\hline \multicolumn{7}{|c|}{ Nil(0), Mild(1), Moderate(2), Severe(3) } \\
\hline
\end{tabular}

\subsection{Results Interpretations}

From the study, it was found that each person suffered pains from one or more parts of their body using the computer.

The result also indicates that more than $90 \%$ of the University Community falls between the ages of 18 and 50 years. Over $87.9 \%$ of the population under study use fix chairs working with computer systems with the rest using adjustable ones. This indicates that, several people will have severe pains due to bad sitting posture while working for a period of time. From the survey, it was discovered about $90 \%$ of interviewees who 


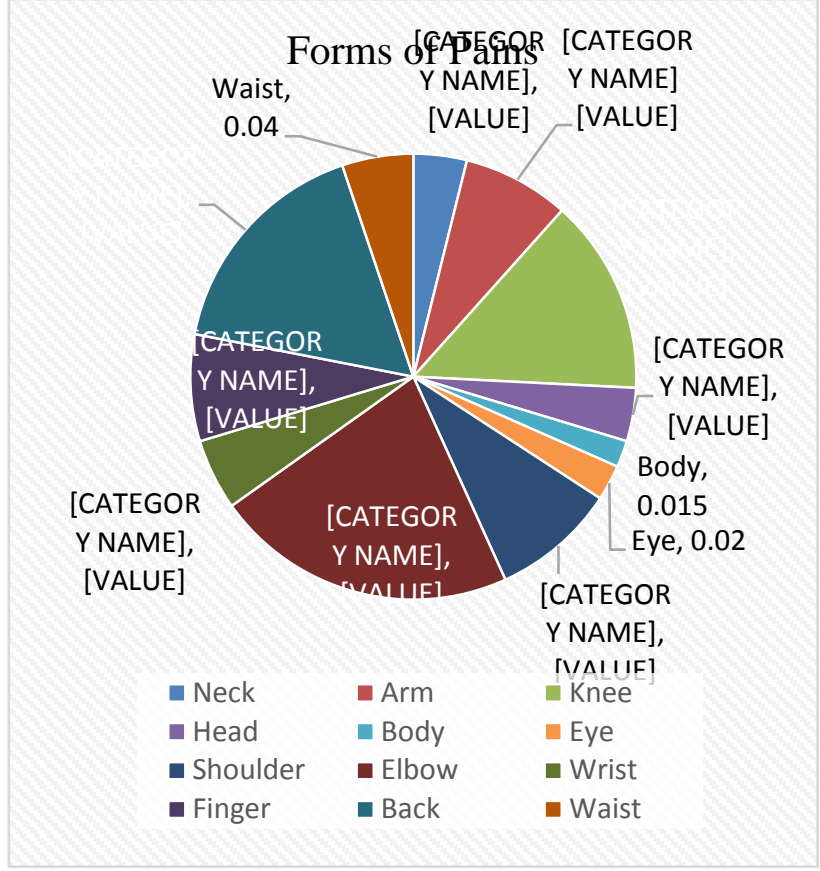

i. Lighting and Vision-Health centered programs must be created, especially in the university to educate students and workers on preventive measures to overcome RSI.

ii. Use of ergonomic alert programs to help users of computer systems to intermittently take breaks from the use of their computers.

iii. Seminars and training programs to create the awareness of safety measures and working conditions for all computer users. Such remedy can prevent accidents at work.

iv. Computer users have to deal with the habit of taking short breaks during the day while working on the computers, in order to practice different types of ergonomic exercises.

v. Jobs should provide adequate preventive measures, while those who already have these measures in place constantly check workers adhere to them.

Hence this research generally recommend the need to improve computer work spaces by management in terms of redesigning, awareness creation programs and the use of ergonomic devices across the workplace. This will go a long way in reducing the high record of incidence of RSI due to poor attitude towards the use of computers.

\section{SUMMARY AND CONCLUSION}

\subsection{Conclusion}

Our findings have generally linked long duration of computer usage, usage of ergonomically defective chairs, and bad ergonomic work station to incidence of Repetitive Strain injury. We also discovered that with increased computer literacy in the developing countries, many users' workplaces still lack proper design, management strategies, and task design. This showed that proper attention has not been given to the need to minimizes or eradicate workplace hazard. [6]

\subsection{Recommendations}

Below are some recommendation to create awareness and also curb the increase in Repetitive Strain Injury among computer users in general.

\section{REFERENCES}

[1] Abdul Rahman, Z. and Atiya, A.S. (2009). Prevalence of Work-related Upper Limbs Symptoms (WRULS) Among Office Workers. Asia Pac. J Public Health. 21(3):252258.

[2] Adedoyin R. A, Idowu B.O, Adagunodo R. E \& Idowu P.A (2005): "Musculoskeletal pain associated with the use of computer systems in Nigeria", IOS Press Amsterdam, The Netherlands, the Netherlands. Vol. 13 issue 2, p125-130.

[3] Allen E. (2007): "Occupational Overuse Syndrome (OOS): a recurring problem in the Computer Industrially developing Countries (IDCs) a case study at University of Benin, Benin City Nigeria." HFES Journal, Ergonomics Australia Vol. 21, References.

[4] Aptel, M., Aublet-Cuvelier, A. \& Cnockaert, J.C., (2002). Work-related musculoskeletal disorders of the upper limb. Joint, bone, spine: revue du rhumatisme, 69(6), pp.546-55. Available at: http://www.ncbi.nlm. nih.gov/pubmed/12537261 (Accessed November 30, 2016).

[5] Gerr, M. D., Marcus, M., Ensor, C., Kleinbaum, D., Cohen, S., Edwards, A., Gentry, A., Ortiz, D., and C. Monteilh. (2002). A prospective study of computer users: I. Study design and incidence of musculoskeletal symptoms and disorders, American Journal of Industrial Medicine 41 (4): 221-235.

[6] IntelRealSense, (2014). SDK Design Guidelines. Available at: http:// www.intel.com/ realsense (Accessed November 28, 2016).

[7] Lin,Y.H., Chen, C.Y., Lu S.Y. (2009). Physical discomfort and psychosocial job stress among male and female operators at telecommunication call centers in Taiwan, Applied Ergonomics; 40(4): 561-568

[8] United States Department of Labor. (2001). Lostworktime injuries and illnesses: Characteristics and resulting time away from work, 1999. http://www.bls.gov/iif/ [Accessed 5 May 2001]

[9] Silman and Newman (1996) A "Review Of Diagnostic Criteria For Work Related Upper Limb Disorders (WRULD)" Semantic Scholar

[10] Vivienne G. and Norman J.(2001) "The Typing Injury FAQ, Motion-Based Ergonomics Keyboard Retraining" Available on http://www.tifaq.org/ergonomics.html (Accessed on 22/04/2010)

[11] Webster J. and Gonzalez M. (2006): "Repetitive Strain Injury" Fact Sheet AHS-06 Uttah State University Cooperative Extension, available at extension.usu.edu/agriculturehealthand safety accessed on $04 / 05 / 2011$

[12] Wellnomics Limited. (2000). RSI - A US perspective. Wellnomics Limited White Paper. 